\title{
Writing in the Foreign Language Classroom: The Effects of Prompts on the Iranian Learners of English
}

\author{
Soroush Bahrebar (Corresponding author) \\ M.A graduate in TEFL \\ PO Box 37147-53517, Tehran, Iran
}

Tel: 98-912-4580-790 E-mail: Motarjem33@gmail.com

\author{
Ali Mohammadi Darabad \\ M.A graduate in TEFL \\ PO Box 13518-57195, Tehran, Iran
}

Tel: 98-912-7070-951_E-mail: Mohammadi.ali741@gmail.com

\begin{abstract}
Received: March 19, 2013 Accepted: April 6, 2013 Published: April 7, 2013
doi:10.5296/ijele.v1i3.3492 URL: http://dx.doi.org/10.5296/ijele.v1i3.3492
\end{abstract}

\begin{abstract}
The present study intended to inspect whether different prompts (bare, vocabulary, and prose model) could exert different effects on the overall quality of the Iranian intermediate EFL learners' writing performances or not, and in case of effect, which of the prompts was efficacious toward the enhancement of the participants' overall writing quality. Forty male and female Iranian intermediate students learning English as a foreign language were selected via administering the Preliminary English Test (PET) and were each given three different writing prompts (bare, vocabulary, and prose model) during three consecutive weeks to write. The writing tasks involved the descriptive mode of discourse. Each task was presented in the context of a reply to an imaginary pen pal from England, Jack. A close examination of the results manifested the fact that the prose model elicited the best overall writing quality in the descriptive discourse mode when evaluated holistically. The bare prompt typically resulted in the poorest writing. The vocabulary prompt elicited writing samples that usually were of higher overall quality than those obtained with a bare prompt, but of lower quality than samples obtained with a prose model prompt.
\end{abstract}

Keywords: Prompts, Writing, Composition, Second language writing instruction 


\section{Introduction}

In many societies, writing is an essential tool for communication, learning, and self-expression. Through writing individuals are able to maintain personal links with friends, family, and colleagues from a distance. Writing also makes it possible to collect and convey information with accuracy and detail. Individuals can further record their ideas, reflect on their thoughts, or extend their knowledge on a topic through the use of writing. The National Commission on Writing for America's Families, Schools, and Colleges (2004) described writing as a threshold skill for employment and promotion and indicated that people who cannot write well are less likely to be hired, retained, and/or promoted.

Concerns about the writing achievement of students in countries whose language are not English and even in the U.S schools have been present for many years and continue to persist. According to the Utah Criterion-Referenced Tests (CRT) (2008-2009), many students experience difficulties mastering writing.

One of the reasons for such a difficulty can be attributed to the fact that writing skill has received the least attention due to its complexity and to the commonly accepted idea that mastery of this skill is, in fact, an impenetrable territory for a foreign language learner.

Historically, those engaged in Teaching English as a Foreign Language (TEFL) have given little sustained attention to the development of the writing ability in the learners. According to Blaya (1997), most EFL practitioners have taken the position that writing is a secondary or less crucial skill than listening, speaking, and reading. He further states that despite a large number of studies analyzing the way writers compose in second language settings, research on EFL writing is quite scarce.

The complexity of the writing skill and the wrongly-held views about writing as being a secondary skill may account for the paucity of EFL writing research. Among the small number of researches in the realm of writing, only few have been conducted to deal directly with the instructional procedures for teaching second language (L2) writing (e.g., Bougey, 1997; Terry, 1989; Wei, Shang, \& Briody, 2012).

The present study seeks to take a step out of theoretical linguistic frameworks to the more practical ones by exploring the efficacy of three different prompts (bare, vocabulary, and the prose model) on the quality of the writing of Iranian learners of English. It goes without saying that elucidation of these practical steps will itself contribute extensively to theoretical constructs in this respect.

How do I write this? How do I get started? What should I write? These questions may originate, among other sources, from the learners' lack of the necessary background knowledge about the topic to write, or their lack of trigger to activate their existing background knowledge. Prompts can serve as triggers; they can show the writers the places to start writing.

The question of how different prompts (bare, vocabulary, and prose model) would affect the quality of the writing of Iranian learners of English is investigated in this attempt to check the 
interaction between the models in question and learners' degree of achievement and at the same time to find the superiority of one model to the other. This study attempts to contribute to the illumination of writing processes by arriving at results which are applicable to instructional circumstances; it aims at solving some practical problems concerning FL learners' writing skills. In this perspective, therefore, the study gains significance and as a result can shed more light on developing materials and on the ways teachers approach writing instruction. Considering the significance of the role of prompts in composition writing, this study aims at exploring the efficacy of three different prompts (bare, vocabulary, and prose model) on quality of the writing of Iranian learners of English.

\section{Literature Review}

\subsection{Introduction}

There is little consensus among researchers to give a clear definition of writing; however, this lack of consensus reflects the complexity of the process. Writing has been defined in a variety of ways. Some define it as a thinking process (Flower \& Hayes, 1990). According to Flower and Hayes (1990), "writing is a straightforward act of saying what the writer can mean, the mental struggles writers go through, and the interpretations readers make" (p. 172).

Writing is so complex that one will not be able to give his/her student a simple formula for good writing. One must try to give the student an awareness of the complexity of the process in order to meet their writing objectives (Mackay, 1995). Mackay further adds that "Writing is a dynamic process which involves such activities as generating ideas, setting goals, planning, evaluation, and revising" (p. 258).

Some researchers believe that teaching ESL/EFL to student to acquire writing skill is by no means easy, and that learning to write is a complex process which takes long practice and extensive experience (e.g., Flower \& Hayes, 1990).

Halliday (1999) refers to writing as "learning how to mean." He states that writing is a communicative activity; therefore, it is carried out in accordance with certain general principles which underlie the use of language in communication.

\subsection{Nature of Writing}

Most people are seen to have difficulty in getting their thoughts down on paper, and for them it is usually an ordeal to be avoided whenever possible; but to others, it is a common experience of whatever complexity it may be. Writing is one of the most authentic and reliable ways of transferring thoughts to others. Learning to write is regarded as the acquiring of basic skills on which other, later and probably more important, skills can be built, and without which further education may be largely impossible (Cooper \& Odell, 2003).

Learning to write in any language whether it is one's first, second or third language continues to be a major educational undertaking throughout the world. Learning to write in English, however, can mean many things. The ability to write something, even if it is called on only to get down shopping lists, is at least one aspect of minimal literacy. At the other extreme, it is the ability to produce major creative works of literature of long research studies (Barnett, 
1989).

In Bereiter and Scardomalia's (1987) terms, writing a long essay is probably the most constructive act that most human beings are ever expected to perform.

In the second language context writing is even more complicated since it is not only the matter of trying to master a different medium and learning how to handle it; it is also a matter of learning how to express oneself appropriately in a different language and in a different culture. Halliday (1999) considers writing as a communicative activity; therefore, it is carried out in accordance with certain general principles which underlie the use of language in communication. Communication itself is a matter of information of various kinds, from the context of A's world knowledge to that of B's, and those linguistic rules facilitate the transference. The process of writing rarely proceeds in a linear fashion. Various components of writing such as generating ideas, organization, grammar and diction are called into play throughout the writing process.

The quality of texts produced in a second language has also been shown (Cumming et al., 1999). Given the demanding nature of second-language composing processes, composition researchers and teachers have begun to acknowledge the positive role of the first language in second-language writing. Second language writers have been observed to employ their first language to "get a strong impression and association of ideas for essays" and produce essays "of better qualities in terms of ideas, organization and details" (Lay, 1991, p. 406) and to "meaningfully link image to word" (Spack, 1991, p. 664). They have also been found to use their native language as "an important resource in their continual processes of decision making while writing" (Cumming et al., 1999, p. 128). Although the use of the first language by second-language learners has long been criticized, primarily due to first-language interference (Lado, 1990), renewed attention seems to have been directed to first-language use in the processes of composing in a second language.

Following advances in mother-tongue writing instruction (reviewed in Bereiter \& Scardamalia, 2003), many authors have argued that instruction on writing processes in a second language can form a basis for overcoming the artificial separation between language instruction and intellectual or sociocultural development imposed by conventional language curricula (Cumming et al., 1999; Edelsky, 2006; Mackay, 1995; Urzua, 2006). Current approaches to writing instruction in a second language advocate the negotiation of meaning between student writers and their audiences, sequential processes of drafting and revising composition, and the development of learners' abilities to diversify their capacities for written expression.

Both Edelsky (2006) and Urzua (2006) argue that second language writing should involve linguistic, social and cognitive processes.

\subsection{Prompts}

Regardless of the pedagogy of any given writing program, in the academic world, students are frequently evaluated on the basis of writing products they produce in response to various writing topics in a variety of circumstances. In testing situations, the stimulus for the student 
to respond to is referred to as a prompt. Prompts are not topic. In other words, they do not set down limits to what can be written about. They are merely places to start writing. Special consideration should attend the preparation of writing prompts when there are a significant number of test-takers who are nonnative speakers of English. Writing prompts must be carefully prepared by test developers so that the student has the best possible chance to demonstrate accurately his/her true level of writing skills (Kroll \& Reid, 2003). For the purpose of this study prompts have been categorized as follows:

Bare prompt: A type of writing stimulus (topic) containing nothing more than pure sentences requiring writers to write about a subject (e.g., appendix A).

Vocabulary prompt: A writing stimulus (topic) which presents vocabularies needed to write about a specific subject (e.g., appendix B).

Prose model prompt: A writing stimulus (topic) which presents a model of a paragraph or more of a similar type of writing to show the writers how to write about the subject (e.g., appendix $\mathrm{C}$ ).

Witte (2007) reported that when native speakers were asked to write compositions in response to various prompts, it became obvious that not all prompts produced similar results across groups, even though the prompts had been devised to be topics with which all students would be familiar.

The topics to which students are asked to respond in composition would appear to make a difference in the quality of writing that students produce; however, research in the area of topic is sorely lacking. As Hoetker (2000) says, "there is little hard evidence anywhere that students will write any worse (or any better) on topics such as those I have just criticized than on the most thoughtfully considered and carefully edited topics" (p. 14).

The research that exists is not only far from conclusive, but often produces conflicting results. Hoetker (2000) discusses the extreme difference in quality that was found in the compositions produced by students taking the California State University and College Equivalency Examination between the years 1973 and 1974. Pytlik (2001) reports on a study conducted by Jones, whose finding showed that students performed better with textbook topics than with topics of their own. Moreover, Greenberg (1981), expecting that topics that asked students for their personal experience would produce better compositions, was surprised to find that students' writing performance was not significantly affected by the type of essay question to which they responded.

Brossell and Ash (1984) found that students wrote more organized, more sharply focused, and more fluent essays on the topic of violence in the schools.

These studies on topic and composition proficiency have been conducted with native speakers of English. There is little research that provides much insight into the ways topics influence the native-speaker writing, and the picture is even bleaker when it comes to nonnative-speaker writing. As Hoetker (2000) states: "We know little about topic variables because research attention has been devoted almost entirely to issues of rater reliability, 
ignoring for the part the issue of validity as well as the other two sources of error in an essay examination-the topics and the writer" (p. 247).

\subsubsection{Prompt Difficulty}

In a review of literature in L1 writing, Huot (2005) discusses a number of prompt factors that affect writing tests' scores including, among others, discourse mode or purpose for writing (Hoetker, 2000; Quellmaiz, Capell, \& Chou, 1982), and degree of rhetorical specification (Brossell, 2000). Defining what is meant by prompt difficulty is not as straightforward as it may seem. Prompt difficulty is usually thought of in terms of scores, that is, prompt that elicit lower scoring essays are considered more difficult than those that elicit essays receiving higher scores.

A number of features (e.g., subject matter, rhetorical specification) have been identified that possibly contribute to prompts being easier or more difficult. Test taker characteristics such as gender and language background have also been identified that may interact with these features. These are as follows:

\subsubsection{Subject Matter}

First is subject matter or topic domain. While the topics used in exams are presumed to be familiar to all test takers, it remains that some test takers may have more expertise in a particular subject (e.g. medical professionals asked to talk about doctors) and thus have an advantage over other test takers. In Polio and Glew's (1996) study on how students choose writing topics, the most often-cited reason was having background knowledge and perceived familiarity with the topic. These were also the reasons cited for choosing a topic in Powers and Fowles (1998). However, that test takers are more familiar with a topic does not necessarily mean that they will perform better on them. Test takers in Powers and Fowles did no better on topics they preferred. When the English Language Testing System was being revised, the plan to divide test takers into six discipline areas was abandoned when it was found that there were no systematic differences in test-takers' performances when responding to general and field specific prompts (Hamp-Lyons, 1990). On the other hand, Tedick (1990) reports that ESL graduate students did better on topics specific to their field than on general topics.

\subsubsection{Rhetorical Task}

Studies on the type of writing called for in a prompt have by and large compared personal versus impersonal writing, or narrative versus argumentative writing. A number of studies have investigated performance on prompts that invited a personal, first person response versus those that called for impersonal, third person responses (Brossell \& Ash, 1984; Greenberg, 1981; Hoetker \& Brossell, 1989). These studies found no significant differences, though this lack of finding can perhaps be attributed to the cues being so subtle that test takers were not likely to pick up on them.

\subsubsection{Task Specification}

The way prompts are specified has received some amount of attention. A number of studies 
have looked into the amount of information provided in the prompt. Kroll and Reid (2003) divide prompts into three categories: bare prompt, framed prompt, and text-based or reading based prompt. The first is stated in relatively direct and simple terms (e.g., Do you favor or oppose $\mathrm{x}$ ? Why?); the second presents a situation or circumstance, and the task is in reference to this; and the third has test takers read texts of some length and then interpret, react to, or apply the information in those readings. For his part, Brossell (1983) divides the first two categories into prompts that have low, moderate, and high information load. Brossell found that a medium level of specification resulted in longer essays and higher scores, though differences were not significant overall. In O'Loughlin and Wigglesworth (2007), tasks with less information elicited more complex language, but this difference in production did not affect scores.

\subsubsection{Test-Taker Characteristics}

Investigations of test-taker characteristics that could interact with prompt-related factors have focused on gender, language background, and proficiency level. Where test-taker gender is concerned, Breland, Bridgeman, and Fowles (1999), Breland, Lee, Najarian, and Muraki (2004), and Broer, Lee, Rizavi, and Powers (2005) have found instances of differential item functioning (DIF) in favor of female test takers in six different performance writing tests, to a magnitude up to 0.2 of a standard deviation. The authors caution though that the direction and size of the differences are highly sensitive to sample selection, and the findings should not be generalized beyond the exams studied.

Studies have also considered the different production of writers from different language backgrounds on different tasks (Park, 1988; Reid, 1990). Reid, for example, studied the performance of writers whose first languages were Arabic, Chinese, English, or Spanish on a comparison and contrast task and on a graph/data commentary task. She found that writers from three of the language backgrounds, with the exception of the Spanish group, showed greater production on the graph task. There was also greater use of passive-voice in the comparison and contrast task for Arabic and Chinese writers, but not for English and Spanish writers. In Park's study, differences in production were found according to language background and area of academic specialization.

Based on the brief review of the literature we attempted to investigate how different prompts (bare, vocabulary, and prose model) would affect the quality of the writing of Iranian learners of English and to check the interaction between the models in question and learners' degree of achievement and at the same time to find the superiority of one model to the other. This study attempts to contribute to the illumination of writing processes by arriving at results which are applicable to instructional circumstances; it aims at solving some practical problems concerning EFL learners' writing skills.

\section{Methodology}

\subsection{Participants}

Sixty male and female Persian EFL students studying in Qom Islamic Azad University in English Translation major field were randomly chosen to attend this study. Of these 
participants 40 ones were selected based on the scores obtained from preliminary English test.

\subsection{Materials}

A Preliminary English Test (PET) (2011) was used to homogenize the participants at intermediate level in this study. The writing tasks involved a single mode of discourse namely, descriptive. Each task was presented in the context of a reply to a pen pal from the United States, Jack.

The three types of writing prompts designed for this study consisted of a bare prompt, a vocabulary prompt, and a prose model prompt. The bare prompt was a simple explanation of the task presented in English only. The vocabulary prompt also contained a list of words in English with their Persian equivalents. The prose model prompt was a composite model pen pal letter complied from authentic letters (appendix $\mathrm{C}$ ). The bare prompt required students to describe an experience of walking through a park in spring on a beautiful day (appendix A). The vocabulary prompt required them to write a brief account of their country (appendix B), and the prose model prompt asked them to describe transportation in their cities.

\subsection{Procedures}

For the purpose of this study, after the random selection of participants, the Preliminary English Test (PET) (2011) was administered for homogenizing our experimental sample. Three writing samples were collected from each student during three consecutive weeks. The instructions from a prepared script were read to them, making sure students read the directions carefully, were aware of the sixty-minute time limit, and did not use any reference materials or other resources to complete the task. As an incentive, students were told that they would receive marks for completing each task to the best of their ability. The same procedure was followed each time a writing sample was collected.

Michigan Writing Assessment Scoring Guide for holistic scorning served as the basis for training the three teachers who scored the writing samples. During a session the three raters learned the scoring rubrics and reached an inter-rater reliability of .81 for the fifteen anchor papers they scored (SPSS 18). In an effort to control rater bias in the scoring, the prompts were deleted from the papers given to the raters to evaluate.

\section{Results}

After collecting the required data, ANOVA and Scheffe tests were used as the statistical instruments to find out if different prompts (bare, vocabulary, and prose model) would exert different effects on the quality of the participants' writings.

The type of AVONA used in this study was a one-way, since there was one dependent variable (the overall quality of the writing) and one independent variable (prompt) consisting of three levels (bare, vocabulary, and prose model). Scheffe Test was used to clarify the precise location of differences. ANOVA along with Scheffe Test allows the researcher to discover the way different prompts (bare, vocabulary, and prose model) affect students' writing performances. 
The final number of writing samples collected was 93 out of the total possible 120 samples. Some samples were not collected because of absence. These absences were for typical reasons (e.g., sickness) and therefore did not systematically bias the results. Table 1 presents the means and the standard deviations of the subjects in the three different prompt groups.

Table 1. Mean and the standard deviation of the groups

\begin{tabular}{llll}
\hline Prompt & $\mathrm{N}$ & Mean & $\mathrm{SD}$ \\
\hline Bare & 31 & 2.2580 & 1.2374 \\
Vocabulary & 31 & 2.7741 & 1.2834 \\
Prose model & 31 & 3.9677 & 1.2775 \\
\hline
\end{tabular}

Table 2. Test of between and within subject analyses

\begin{tabular}{llllll}
\hline & Sum of Square & df & Mean Square & F & Sig. \\
\hline Between Group & 47.677 & 2 & 23.839 & 14.866 & .000 \\
Within Group & 144.323 & 90 & 1.604 & & \\
Total & 192.000 & 92 & & & \\
\hline
\end{tabular}

$* \alpha<.05$

The results of the analysis in Table 2 indicate that the means differences are significant $(p<.05)$. Following the finding that the overall $\mathrm{F}$ in the between group test was statistically significant, Scheffe Test-the most commonly used and the most conservative method of post hoc comparisons was run to find the precise location of differences and the following results were obtained (Table 3):

Table 3. Post hoc Scheffe test

\begin{tabular}{lllll}
\hline Var. (I) & Var. (J) & MD(I-J) & Std. Error & Sig. \\
\hline \multirow{2}{*}{ bare } & Voc. & -.5161 & .3216 & .281 \\
& Prose & $-1.7097^{*}$ & .3216 & .000 \\
Voc. & Bare & .5161 & .3216 & .281 \\
& Prose & $-1.1935^{*}$ & .3216 & .002 \\
Prose & Bare & $1.7097^{*}$ & .3216 & .000 \\
& Voc. & $1.1935^{*}$ & .3216 & .002 \\
\hline
\end{tabular}

* The mean difference (MD) is significant at the .05 level 
The results of the Scheffe Test revealed that the significant differences were between the means of the subjects who performed the writing task with the prose model prompt and those who performed with the bare and the vocabulary prompts. The mean difference of the subjects who wrote with the bare and the vocabulary prompts was not significant $(p<.05)$.

\section{Discussion and Conclusion}

The attained outcomes of this experiment designated that the learners who were prompted by the prose model prompt outperformed the learners in the other two groups who wrote with the bare and the vocabulary prompts.

The prose model elicited the best overall writing quality in the descriptive discourse mode when evaluated holistically. The bare prompt typically resulted in the worst writing. The vocabulary prompt elicited writing samples that usually were of higher overall quality than those obtained with a bare prompt, but of lower quality than samples obtained with a prose model prompt.

The prose model prompt in this study seems to have offered students a more effective stimulus for writing than a bare prompt or a vocabulary list. Given that the students performed better on the overall quality (holistic score), one might assume that these students simply copied the pen pal letter or altered it only slightly. The researchers' examination of their responses, however, did not indicate that this was the case. Students' papers contained mistakes of form that could have been avoided by copying the model. The personalized content of the students' letters indicates that the prose model was taken as a real letter to be read and answered.

The findings of this study support the view of the efficacy of the prompts on the quality of the writing which has been held by some experts of the field. Quellmaiz, Capell, and Chou (1982) believe that the discourse mode or the purpose for writing associated with the prompts affect scores on writing tests. Brossell (2000) claims that the degree of rhetorical specification presented in the writing prompts can exert significant effects on the quality of the writer's performances.

Witte (2007) reported that various prompts produce various results across the writers. The effectiveness of the prose model prompt enforces the idea of reading-writing connection. The only source of knowledge sufficiently rich and reliable for learning about written language is the writing already done by others. In other words, one learns to write by reading; our desire to write provides an incentive and direction for learning about writing from reading. But the writing that anyone does must be vastly complemented by reading if it is to achieve anything like the creative and communicative power that written language offers. Fitzgerald (1999) argues that writing and reading, or, more specifically, such sub processes of writing and reading as revision in writing and critical reading are "highly related and draw on similar thought processes" (p. 2). The interrelationship between reading, writing, and thinking can be further supported by Vygotsky's (1978) work. He established a basis for his theory of the relationship between thought and word, by suggesting that words give rise to thoughts, which, in return, are expressed in words. 
Proponents of the whole language approach to teaching reading and writing emphasized active involvement of students into reading and writing process (Goodman \& Goodman, 1997), and de-emphasized teaching of discrete skills. In the 1990s, teachers and researchers have become increasingly aware of teaching reading and writing as means to acquire context knowledge and to develop academic writing skills. The idea of reading and writing as modes of learning is further fortified by the current social-constructivist theory of learning (Vygotsky, 1978). The present experiment can disprove the view which assumes writing a FL nothing more than translating word for word from L1 to FL with little regard for linguistic, rhetorical, and cultural differences between the L 1 and the FL. This study showed that the process of writing rarely proceeds in a linear fashion. Rather various components of writing such as generating ideas, organization, grammar as well as diction are called into play throughout the writing process.

Writing is a communication skill, and FL writing instruction can and should include real-life tasks. Vygotsky (1978) stressed the importance of meaningful social interaction in language acquisition. A letter exchange between students of the source language and those of the target language, whether via electronic mail or conventional mail, would provide ample authentic models to FL writing instruction while, at the same time, fostering cross-cultural communication and furnishing students with a source of written input.

\subsection{Implications for the EFL Writing Classroom}

The results of the current study can infer some possible pedagogical implications practical for the FL writing classroom:

1. Reading and writing should not be taught discretely if we are not to deprive the students of the simultaneous enjoyment of the two independent means to acquire content knowledge for developing writing skills.

2. Writing tasks should be so designed as to let the students benefit from reading before they start to write. This can give the students opportunities either to create themselves required background knowledge about the subject matter or to have their already existing background knowledge activated. The prose model prompt can serve this purpose.

3. FL teachers should be mindful of the writing tasks and prompts they assign. Arbitrary assignments, such as writing a description of oneself for the teacher, are devoid of realistic context and remove writing from its communicative and interactive purposes. Responding to letters, such as the pen pal letters in this study, simulates real life social interaction, albeit written. On the one hand, the prose model prompt clearly enabled the students to move toward their potential as writers through interaction with more capable peers, in this case native writers of English. On the other hand, their performance with the bare prompt is, no doubt, more indicative of their ability to undertake writing tasks totally on their own.

4. More in-context vocabulary and more authentic, level-appropriate prose models to read, to analyze, and subsequently to imitate should be included in secondary textbooks. 


\section{Macrothink}

International Journal of English Language Education

ISSN 2325-0887

2013, Vol. 1, No. 3

\section{Refrences}

Barnett, M. A. (1989). Writing as process. French Review, 63, 31-44.

Blaya, M. V. (1997). EFL composing skills and strategies: Four case studies. RESLA, 12, $163-184$.

Bougey, Ch. (1997). Learning to write by writing to learn. English Language Teaching Journal, 51(2), 126-134. http://dx.doi.org/10.1093/elt/51.2.126

Bereiter, C., \& Scardamalia, M. (1987). The psychology of Written Composition. Hillsdale, NJ: Lawrence Earlbaum. PMid:3665465

Breland, H., Bridgeman, B., \& Fowles, M. (1999). Writing assessment in admission to higher education: Review and framework. College Board Report, 99-03. Princeton, NJ: Educational Testing Service.

Breland, H., Lee, Y. W., Najarian, M., \& Muraki, E. (2004). An analysis of TOEFL CBT writing prompt difficulty and comparability for different gender groups. TOEFL Research Reports, RR-04-05. Princeton, NJ: Educational Testing Service.

Broer, M., Lee, Y. W., Rizavi, S., \& Powers, D. (2005). Ensuring the fairness of GRE writing prompts: Assessing differential difficulty. ETS Research Report, RR 05-11. Princeton, NJ: Educational Testing Service.

Brossell, G. (2000). Rhetorical specification in essay topics. College English. 45, 165-173. http://dx.doi.org/10.2307/377224

Brossell, G. (1983). Rhetorical specification in essay examination topics. College English, 45(2), 165-173. http://dx.doi.org/10.2307/377224

Brossell, G., \& Ash, B. H. (1984). An experiment with the wording of essay topics. College Composition and Communication, 35(4), 423-425. http://dx.doi.org/10.2307/357794

Candling, C. N., Kirkwood, J. M. (1987). Study skills in English. London: Longman.

Cooper, C. R., \& Odell, L. (2003). Holistic Evaluation of Writing. Urbana, IL: National Council of Teachers of English, 3-31. PMid:14516368

Cumming, A., Rebuffot, J., \& Ledwell, M. (1999). Reading and summarizing challenging texts in first and second languages. Reading and writing, 2, 201-219.

Edelsky, C. (2006). Writing in a bilingual program: The role of L1 and L2 texts. TESOL Quarterly, 16(2), 211-228. http://dx.doi.org/10.2307/3586793

Fitzgerald, J. (1999). Enhancing two related thought processes. The Reading Teacher, October 1989, 42-48.

Flower, L. S., \& Hayes, J. R. (1990). The dynamics of composing. Hillsid, New Jersy: Lawrence Earlbaum Associates(165).

Goodman, K. S., \& Goodman, Y. M (1997). Learning about psycho logistic processing by 
analyzing oral reading. Harvard Educational Review, 47, 3, 317, and 32.

Greenberg, K. (1981). The effects of variations in essay questions on the writing performance of CUNY freshmen. New York: The City University of New York Instructional Resource Center.

Halliday, M. A. K. (1999). Context and text: Aspects of language in social-semiotic perspective. Oxford: Oxford University Press (130). PMid:10447724 PMCid:2326811

Hamp-Lyons, L. (1990). Second language writing: Assessment issues. In B. Kroll (Ed.), Second language writing: Research insights for the classroom (pp. 69-86). Cambridge: Cambridge University Press. http://dx.doi.org/10.1017/CBO9781139524551.009

Hoetker, J. (2000). Effects of essay topics on student writing: A review of the literature. ERIC ED, 15, 214-486.

Hoetker, J., \& Brossell, G. (1989). The effects of systematic variations in essay topics on the writing performance of college freshmen. College Composition and Communication, 40(4), 414-421. http://dx.doi.org/10.2307/358240

Huot, B. (2005). Reliability, validity, and holistic scoring. College Composition and communication, 41, 201-213. http://dx.doi.org/10.2307/358160

Kroll, B., \& Reid, J. (2003). Guidelines for designing writing prompts. Journal of Second Language Writing, 3(3), 231-250. http://dx.doi.org/10.1016/1060-3743(94)90018-3

Lado, R. (1990). Linguistics across cultures. Ann Abor, MI: The University of Michigan Press. PMCid:1062511

Lay, N. D. S. (1991). Composing processes of adult ESL learners: A case Study. TESOL Quarterly, 16, 406-407.

Mackay, S. (1995). Composing in a second language. Cambridge: Newbury house Publications.

National Commission on Writing for America's Families, Schools, and Colleges. (2004). Writing: A ticket to work...or a ticket out. New York, The College Entrance Examination Board.

O’Loughlin, K., \& Wigglesworth, G. (2007). Investigating task design in academic writing prompts. In L. Taylor \& P. Falvey (Eds.), IELTS collected papers: Research in speaking and writing performance (pp. 379-421). Cambridge: Cambridge University Press.

Park, Y. M. (1988). Academic and ethnic background as factors affecting writing performance. In A. C. Purves (Ed.), Writing across languages and cultures: Issues in contrastive rhetoric (pp. 261-272). Newbury Park, CA: SAGE Publications. PMid:3416532

Polio, C., \& Glew, M. (1996). ESL writing assessment prompts: How students choose. Journal of Second Language Writing, 5(1), 35-49. http://dx.doi.org/10.1016/S1060-3743(96)90014-4 


\section{Macrothink}

International Journal of English Language Education

ISSN 2325-0887

2013, Vol. 1, No. 3

Powers, D. E., \& Fowles, M. E. (1998). Test takers' judgments about GRE writing test prompts. ETS Research Report, 98-36. Princeton, NJ: Educational Testing Service.

Pytlik, B. P. (2001). Designing effective writing assignments: What do we know? ERIC ED, 16, 291.

Quellmaiz, E. S., Capell, F., \& Chou, C. P. (1982). Effects of discourse and response mode on the measurement of writing competence. Journal of Educational Measurement. 19, 241-258. http://dx.doi.org/10.1111/j.1745-3984.1982.tb00131.x

Reid, J. (1990). Responding to different topic types: A quantitative analysis from a contrastive rhetoric perspective. In B. Kroll (Ed.), Second language writing; Research insights for the classroom (pp. 191-209). Cambridge: Cambridge University Press. http://dx.doi.org/10.1017/CBO9781139524551.017

Spack, R. (1991). Invention strategies and ESL composition student. TESOL Quarterly, 18, 649-670. http://dx.doi.org/10.2307/3586581

Tedick, D. J. (1990). ESL writing assessment: Subject-matter knowledge and its impact on performance. English for Specific Purposes, 9(2), 123-143. http://dx.doi.org/10.1016/0889-4906(90)90003-U

Terry, R. M. (1989). Teaching and evaluating writing as a communicative skill. Foreign Language Annuals, 22, 43-54. http://dx.doi.org/10.1111/j.1944-9720.1989.tb03142.x

Urzua, C. (2006). You sopped too soon: Second language children composing and revising. TESOL Quarterly, 21, 279-304. http://dx.doi.org/10.2307/3586736

Vygotsky, L. S. (1978). Mind in society. Cambridge, MA: Harvard University Press.

Witte, S. C. (2007). The influence of writing prompts on composing. Paper presented at CCCC, St. Louis.

Wei, Z. F., Shang, H. F., \& Briody, P. (2012). The relationship between English writing ability levels and EFL learners' metacognitive behavior in the writing process. International Journal of Academic Research in Progressive Education and Development, 1(4), 154-180.

\section{Appendix A}

Write to your pen pal john who lives in England about an experience of walking through a park on a beautiful day in spring.

\section{Appendix B}

Write a brief account of your country to your pen pal Jack who lives in England. Write your paragraphs on: weather conditions.

Make use of the vocabulary aid which follows to help you with your writing.

Sunshine آقتاب

Ice

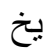




\begin{tabular}{|c|c|}
\hline Rain & بار ان \\
\hline Storm & توفان \\
\hline Flood & سيل \\
\hline Cloud & ابر \\
\hline Wind & باد \\
\hline Drough & خشكسال \\
\hline Mild & معتدل \\
\hline Warm & كرم \\
\hline Humid & شرجي \\
\hline Hot & داغ \\
\hline Icy & بسيار \\
\hline Snowy & برفي \\
\hline Rainy & بار اني \\
\hline Stormy & توفاني \\
\hline Foggy & مه آلود \\
\hline Cloudy & ابري \\
\hline Windy & ير باد \\
\hline Sunny & آفتابي \\
\hline Dry & خشك \\
\hline
\end{tabular}

\section{Appendix C}

Read the following letter that you have just received from your pen pal Jack who lives in England.

Dear friend

This time I want to write a bit about transportation in my city. Public transportation is pretty good in my city. We have an excellent bus system. There are enough modern air-conditioned buses on the routes. The taxi system here can be claimed to be one of the best in the world. The traffic moves quickly, except at rush hours. However, we need more public parking. There is not enough space downtown, so it always takes too much time to find a space.

Write me back soon.

Sincerely Yours

Jack

Now write a letter back to him describing transportation in your city.

\section{Copyright Disclaimer}

Copyright reserved by the author(s).

This article is an open-access article distributed under the terms and conditions of the Creative Commons Attribution license (http://creativecommons.org/licenses/by/3.0/). 